\title{
Indústria de cartucho de toner sob a ótica da remanufatura: estudo de caso de um processo de melhoria
}

\author{
Cícero Ferreira Fernandes Costa Filho \\ Universidade Federal do Amazonas \\ Luís Carlos Barros Coelho Júnior \\ Xerox da Amazônia \\ Marly Guimarães Fernandes Costa \\ Universidade Federal do Amazonas
}

\begin{abstract}
Resumo
Este trabalho apresenta um estudo de caso de um processo de melhoria aplicado a uma indústria de remanufatura de cartuchos de toner. Inicialmente, é feita uma abordagem do processo de remanufatura procurando salientar as principais características que o diferenciam de um processo de manufatura convencional e a importância do mesmo diante das preocupações ambientais atuais. Através de três indicadores de desempenho propostos no trabalho fezse um diagnóstico do processo de remanufatura quanto ao aproveitamento de peças recolhidas do campo, atendimento de pedidos dos clientes e quantidade de defeitos. No diagnóstico inicial realizado, os valores obtidos para esses critérios situaram-se abaixo das metas estabelecidas na empresa. Através da metodologia PDCA, identificaram-se oportunidades de melhorias em pontos críticos do processo de fabricação. A implantação dessas melhorias resultou em ganhos nos indicadores de desempenho da ordem de 12\%. Algumas ferramentas clássicas foram utilizadas para auxiliar na implementação da metodologia PDCA destacando-se brainstorming, diagrama de Ishikawa e Controle Estatístico de Processo.
\end{abstract}

Palavras-chave

Remanufatura, Cartuchos de toner, PDCA, Indicadores de desempenho.

\section{Remanufacturing of toner cartridge: a case study of a improvement process}

\begin{abstract}
This paper presents an improvement process applied in one remanufacturing toner cartridge industry. It, initially, presents a mapping of the stages of this process by attempting to highlight the main characteristics, which distinguish it from a conventional manufacturing process and emphasizes its importance as an of eco-efficient process aiming at achieving sustainable development. Through three performance indicators proposed by the work, a diagnosis of the existing process was carried out as to the reuse of parts gasthered in the field, fulfilment of customers'orders and quantity of production faults. At the initial diagnosis carried out, the values obtained for theses criteria were located below the established targets proposed by the company. Through the PDCA tool, improvement opportunities in critical points in the manufacturing process were identified. The setting up of these improvements resulted in gains in the performance indicators of nearly 12\%. Some classical tools were applied in PDCA implementation, as brainstorming Ishikawa diagram and statistic process control.
\end{abstract}

Key words

Remanufacture, Toner cartridge, PDCA, Quality indicators. 


\section{INTRODUC̣ÃO}

A globalização da economia e o surgimento rápido e contínuo de novas tecnologias impõem-se como forma de mobilizar as organizações para obtenção do grau máximo de competitividade, modernidade e qualidade, de modo a assegurarem sua sobrevivência e crescimento. Nesse contexto, a remanufatura de produtos surge como opção para as organizações no mundo competitivo, estimulando a durabilidade, reduzindo custos e principalmente minimizando o impacto ambiental. A indústria de remanufatura encontra-se atualmente em franca expansão. Às áreas tradicionais de remanufatura, que incluem peças automotivas, máquinas copiadoras e computadores somou-se recentemente a remanufatura de robôs industriais e de telefones celulares. Uma discussão sobre as principais áreas onde a remanufatura é utilizada pode ser encontrada em Steinhilper (2001).

O nível atual de consumo dos recursos naturais justifica essa utilização crescente da remanufatura de produtos. Uma avaliação dos efeitos da atividade humana sobre os recursos naturais pode ser encontrada no relatório planeta vivo da WWF (2004). Um conceito introduzido nesse relatório que nos permite avaliar a degradação dos recursos naturais ocorrida nos últimos anos é o de pegada ecológica. A pegada ecológica mede o consumo de recursos naturais pelas pessoas e é definida como a área da superfície da terra necessária para suprir os recursos naturais consumidos por cada pessoa, considerando as necessidades de alimentos, energia e infra-estrutura social. Segundo o mesmo relatório, no ano de 2001, a pegada ecológica global era de 13,5 mil milhões de hectares, correspondendo a 2,2 hectares por pessoa. Essas exigências sobre a natureza podem ser comparadas com a capacidade biológica da Terra, baseada na sua área biologicamente ativa, que corresponde a um quarto da superfície da Terra. No mesmo ano de 2001 a área produtiva da biosfera traduz-se numa média de 1,8 hectare por pessoa. Assim sendo, no ano de 2001, a pegada ecológica da humanidade excedia a capacidade biológica global em 0,4 hectare por pessoa, ou em $21 \%$. Salienta-se ainda a grande diferença entre os valores de pegada ecológica para países desenvolvidos e em fase de desenvolvimento. No ano de 2001, enquanto os Estados Unidos apresentavam uma pegada ecológica em torno de 10 hectares por pessoa, o Brasil situava-se na faixa de 2,2 hectares por pessoa.

A maioria dos artigos encontrados na literatura sobre remanufatura faz menção aos benefícios ambientais dessa atividade. Williams (2000), em particular, enfatiza que a remanufatura oferece significativos benefícios ambientais, na medida em que reutiliza a energia e os esforços despendidos no processo de manufatura original e evita que resíduos sólidos sejam enterrados ou incinerados. É mister frisar que, para fabricação de um novo cartucho de toner, são consumidos 5 litros de petróleo e que os cartuchos vazios demoram em média 100 anos para serem absorvidos pela natureza (NAGANO, 2000).

Uma comparação de custos entre o processo de remanufatura e o processo de manufatura pode ser efetuada considerando dois itens principais: matéria-prima e mão-deobra. Considerando como fonte de dados a empresa estudada, a economia que se faz em termos de matéria-prima é da ordem de $45 \%$. Esses custos respondem por $80 \%$ do custo total do produto. Em relação à mão de obra, o custo da remanufatura é em média $25 \%$ superior ao custo da manufatura. A justificativa é a maior complexidade dos processos envolvidos com a remanufatura, exigindo um maior nível de empregabilidade. Considerando que a mãode-obra responde por $20 \%$ do custo total do produto, no cômputo final torna-se mais vantajoso produzir um cartucho de toner remanufaturado.

\section{A remanufatura oferece significativos benefícios ambientais.}

Ao introduzir a utilização de peças usadas no processo de fabricação, a remanufatura acrescenta um grau de complexidade a mais em relação à atividade de manufatura convencional. Um entendimento mais amplo sobre todos os aspectos que envolvem a atividade industrial de remanufatura, como mercados e legislação, conceitos de reutilização e reparo, processos de limpeza de produtos, estratégias para obtenção de peças usadas, etc., pode ser encontrado em Steinhilper (2003).

A atividade de remanufatura encontra-se disseminada em uma gama enorme de países, independentemente do seu nível de desenvolvimento. Estudos particulares das perspectivas da atividade de remanufatura em países desenvolvidos e em desenvolvimento, como Inglaterra e Indonésia, respectivamente, podem ser encontrados nos trabalhos de Winifred (1999) e Hanafiah (2003).

O tema deste trabalho, a remanufatura de cartuchos de toner, é abordado no trabalho de Williams (2000). Nesse trabalho, a pesquisa realizada pelos autores procura quantificar a quantidade de material descartável (em oposição à que é reusada) e categorizar as razões do descarte. A partir das razões do descarte, identificam-se fatores relacionados ao design do produto que afetam a atividade de remanufatura do mesmo. Esse conhecimento pode ser utilizado para formular estratégias de design que facilitam a remanufatura. 
O trabalho atual aborda um processo de melhoria implantado em uma indústria de remanufatura de cartuchos de toner, situada no Pólo Industrial de Manaus (PIM), procurando salientar a importância do estabelecimento de indicadores de desempenho e de metas a serem alcançados para os mesmos. Inicialmente, caracteriza-se a atividade de remanufatura em termos de uma formulação matemática simples que leva em conta as entradas e saídas do processo. Em seguida apresenta-se o mapeamento do processo produtivo de cartuchos de toner, os três indicadores de desempenho propostos e a aplicação da metodologia PDCA e de ferramentas complementares no processo de melhoria.

\section{Caracterização do Processo de Remanufatura}

Duas características do processo de remanufatura distinguem-no de forma essencial do processo convencional de manufatura: complexidade do processo de controle de fornecimento de materiais para atendimento à produção e dificuldade no estabelecimento da garantia da qualidade de peças remanufaturadas.

A primeira dessas características, a complexidade do controle de materiais, resulta da variabilidade do percentual de aproveitamento de peças usadas. Um parâmetro relevante da remanufatura associado a esse percentual de aproveitamento é o ratio. Denomina-se ratio o percentual de peças novas que serão acrescidas ao processo de montagem de remanufatura em face do desgaste das peças usadas. Para cada tipo de peça, os valores do ratio e do percentual de peças aproveitadas são dados por:

$$
\begin{aligned}
& \text { ratio }=\left(\frac{\mathrm{p}_{\mathrm{N}}}{\mathrm{p}_{\mathrm{T}}}\right) \cdot 100 \\
& \% \text { peças aproveitadas }=\left(\frac{\mathrm{p}_{\mathrm{A}}}{\mathrm{p}_{\mathrm{R}}}\right) \cdot 100
\end{aligned}
$$

onde:

$\mathrm{p}_{\mathrm{T}}$ : quantidade de peças utilizadas no processo de remanufatura;

$\mathrm{p}_{\mathrm{N}}$ : quantidade de peças novas acrescentadas ao processo de remanufatura;

$\mathrm{p}_{\mathrm{R}}$ : quantidade de peças usadas recolhidas à empresa; $\mathrm{p}_{\mathrm{A}}$ : quantidade de peças usadas aproveitadas na remanufatura.

Devido às peculiaridades da remanufatura, o não recolhimento de $100 \%$ dos produtos manufaturados e o descarte das peças usadas defeituosas ou submetidas a vários ciclos de remanufatura, temos que:

$$
\mathrm{p}_{\mathrm{A}} \leq \mathrm{p}_{\mathrm{R}}<\mathrm{p}_{\mathrm{T}}
$$

O valor do ratio depende das condições e da quantidade de recargas dos cartuchos retornados dos clientes. Esses dois fatores têm forte influência sobre o valor de $\mathrm{p}_{\mathrm{N}}$, que é dado por:

$$
\mathrm{p}_{\mathrm{N}}=\mathrm{p}_{\mathrm{T}}-\mathrm{p}_{\mathrm{A}}
$$

A partir das equações 3 e 4 , vemos que $p_{N}$ é maior do que zero, o que implica dizer que peças novas terão sempre que ser inseridas no processo de remanufatura. Esse raciocínio é válido para um nível de produção estável ou crescente.

$\mathrm{Na}$ Tabela 1 mostramos os principais componentes utilizados na fabricação de um cartucho de toner e os percentuais de substituição, utilizando como fonte dados da empresa estudada. A partir dessa tabela, observa-se que os componentes reutilizados são os plásticos.

A segunda dessas características, a dificuldade de garantia da qualidade de peças remanufaturadas, está associada ao caráter subjetivo da atividade de inspeção de peças usadas. Estabelecer os pontos de inspeção e critérios objetivos de seleção de peças boas são fatores críticos de um processo de remanufatura. Nesse trabalho, através do controle estatístico do processo, identificouse a necessidade de novas inspeções de qualidade em pontos críticos do processo produtivo redundando em ganhos da ordem de $12 \%$ nos indicadores de desempenho propostos.

\section{MATERIAIS E MÉTODOS}

\section{Mapeamento do Processo}

A palavra Remanufatura muitas vezes é confundida com recondicionamento. No entanto, o processo utilizado é totalmente diferente. O produto perde a sua identidade através de um processo de desmontagem total. As peças desmontadas tornam-se matéria-prima que será utilizada na industrialização de um novo produto.

$\mathrm{O}$ processo de remanufatura de cartuchos de toner segue as etapas mostradas na Figura 1 e são listadas a seguir: a) recolhimento dos cartuchos; b) recebimento e armazenagem; c) limpeza grossa (desmontagem); d) limpeza fina, seleção e descarte das peças; e) controle de materiais; f) pré-montagem; g) envasamento dos cartuchos; h) processo de montagem final; i) testes funcionais, ajustes, controle de qualidade; e j) embalagem. A etapa de controle de materiais (item e) não aparece de forma explicita no fluxograma do processo mostrado na Figura 
1, pois está presente implicitamente em todas as etapas do processo produtivo.

Na etapa de recolhimento dos cartuchos, a taxa de retorno dos mesmos situa-se em torno de $80 \%$ dos cartuchos vendidos aos clientes. (Fonte: empresa em estudo). Antes de serem encaminhados a Manaus, os cartuchos sofrem alguns processos, quais sejam: retirada dos resí- duos dos cartuchos e remoção preliminar de cartuchos com defeitos grosseiros. Em seguida os mesmos são enviados para a unidade fabril. O transporte dos cartuchos para Manaus é feito através de três maneiras: transporte aéreo, transporte rodoviário e cabotagem. Esse último, por ser $40 \%$ mais barato que o transporte rodoviário, responde por $70 \%$ do transporte dos cartuchos.

Tabela 1: Percentuais de substituição de componentes utilizados na fabricação de um modelo cartucho de toner.

\begin{tabular}{|l|c|l|}
\hline \multicolumn{1}{|c|}{ MATÉRIA-PRIMA } & PERCENTUAL DE PEÇAS TROGADAS & \multicolumn{1}{|c|}{ MATÉERIA-PRIMA } \\
\hline Etiquetas & $100 \%$ & Desgaste funcional \\
\hline Selos & $100 \%$ & Desgaste funcional \\
\hline Mola & $100 \%$ & Perda de elasticidade \\
\hline Parafuso & $100 \%$ & Desgaste da rosca \\
\hline Material de embalagem & $100 \%$ & Desgaste do material \\
\hline Placas de circuito & $100 \%$ & Tempo de vida útil \\
\hline Relés & $100 \%$ & Tempo de vida útil \\
\hline Lâmpadas & $100 \%$ & Tempo de vida útil \\
\hline Sensores & $100 \%$ & Tempo de vida útil \\
\hline Gabinete & 0 a $100 \%$ & Desgaste funcional \\
\hline Suportes plásticos & 0 a $100 \%$ & Desgaste funcional \\
\hline Covers & 0 a $100 \%$ & Desgaste funcional \\
\hline
\end{tabular}

Fonte: empresa em estudo (2003).

Figura 1: Fluxograma do processo produtivo de remanufatura.

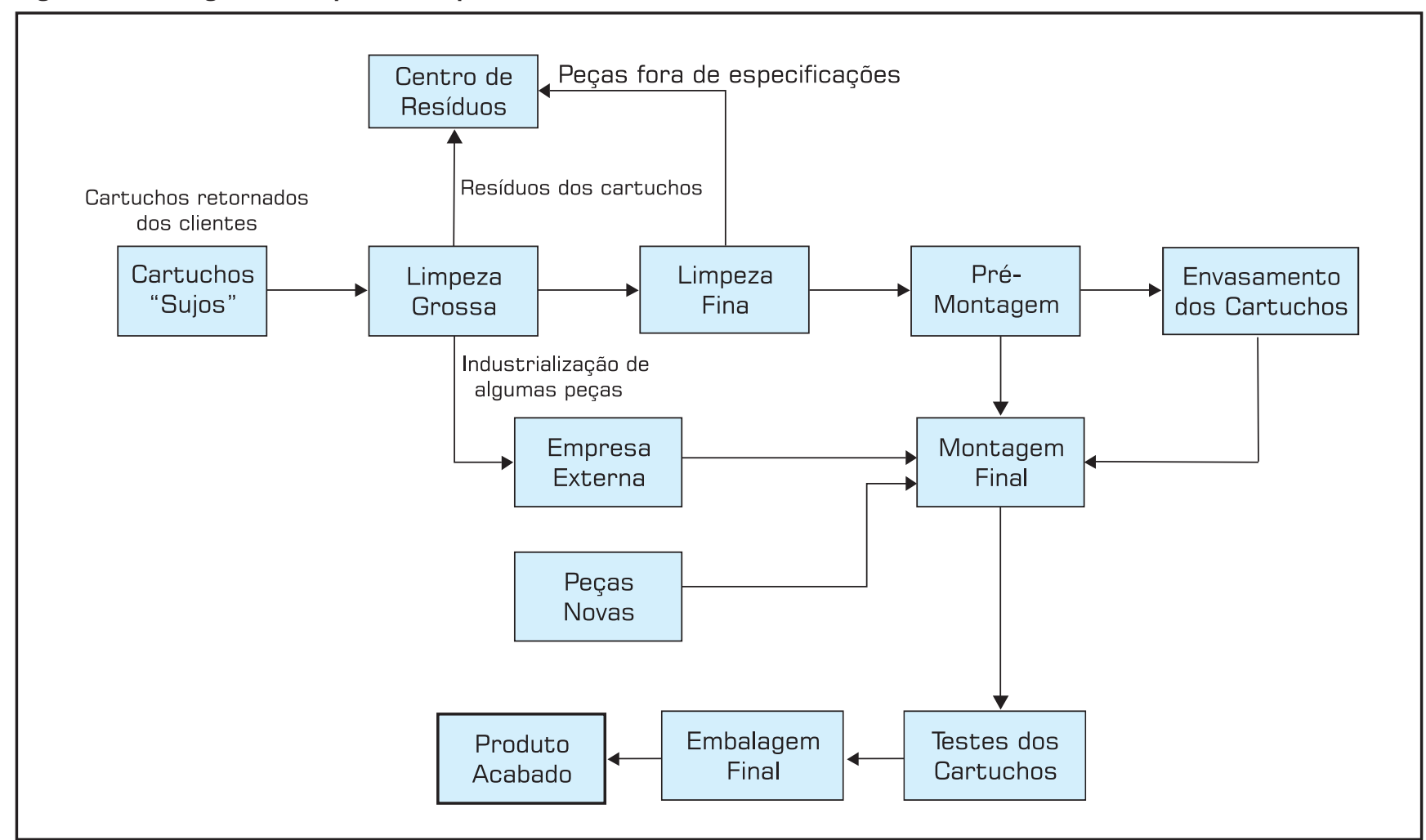

Fonte: empresa em estudo (2003). 
Na etapa de limpeza grossa, para retirada de resíduos de toner e quaisquer outros tipos de impurezas, o cartucho passa inicialmente por um processo de jateamento com ar. Em seguida, dependendo das características técnicas, os cartuchos, sem exceção, são desmontados em componentes ou subconjuntos predeterminados, como guias, suportes, tampas e outros. O controle de materiais marca a sua presença nessa etapa armazenando peças boas oriundas do processo de segregação na limpeza fina, seguindo critérios preestabelecidos, que serão posteriormente utilizadas nas etapas subseqüentes.

e com qualidade adequada. Até então, a unidade se valia apenas de controles internos de produção, voltados para os cumprimentos de planos mensais de produção. Após discussões e análises, o grupo responsável pelo programa de qualidade da empresa chegou a um consenso sobre três indicadores: aproveitamento de entrada, nível de defeitos e nível de entrega. Os dois primeiros refletem o compromisso da qualidade anteriormente expresso, enquanto que o último reflete o compromisso com o cumprimento dos prazos. O primeiro, aproveitamento de entra$d a$, objetivando monitorar o recolhimento de peças usadas, é definido como a razão entre a quantidade de peças aproveitadas e a quantidade de peças recolhidas. O segundo, nível de defeitos, objetivou avaliar o desempenho do processo de fabricação e é definido pela relação entre a quantidade de produtos defeituosos detectados no final do processo e a quantidade total

As principais características da etapa limpeza fina são a utilização de produtos químicos e jatos de água em um processo de lavagem e a inspeção das peças desmontadas, observando defeitos de quebras, empenamentos, riscos e outros danos. Após a limpeza fina as peças são encaminhadas para um estoque de peças remanufaturadas.

Quanto ao número de etapas, o processo de montagem do cartucho remanufaturado é idêntico ao processo convencional de montagem de um cartucho novo, constituindo-se de duas etapas: pré-montagem dos subconjuntos e montagem final. Quanto à origem das peças, o processo de montagem do cartucho remanufaturado difere substancialmente da montagem de um cartucho novo. No primeiro, as peças podem provir de três origens distintas: do estoque de peças usadas, de empresas terceirizadas, que executam a recuperação de peças danificadas, ou do estoque de peças novas. Após montado, o cartucho é envasado. O processo de envasamento, dependendo do grau de participação da mão-de-obra humana, pode ser classificado em três tipos distintos: manual, assistido e automático. Quanto maior o volume de produção necessário maior o grau de automação utilizado.

\section{Indicadores de Desempenho}

Alguns autores (KIYAN, 2001; MARCELLI, 2000) têm enfatizado a importância da utilização de indicadores de desempenho para melhoria do processo produtivo e para um posicionamento estratégico das empresas em um cenário global mais competitivo. A empresa em questão necessitava de um sistema de indicadores de desempenho capaz de concatenar seus objetivos particulares com os objetivos mais gerais da matriz, sintetizados no compromisso com entregas de produtos dentro do prazo produzida. O terceiro, nível de entrega, objetivou avaliar a capacidade do processo produtivo atender as demandas do cliente, retratando o nível de planejamento da atividade produtiva. Esse terceiro indicador é definido como o percentual de pedidos atendidos em um mês. Na Tabela 2 mostramos um sumário desses indicadores.

\section{Metodologia PDCA}

Com o objetivo de atender as metas preestabelecidas para os indicadores de desempenho anteriormente referidos adotou-se a metodologia PDCA, proposta por Deming (1992). Um estudo recente utilizando essa metodologia pode ser encontrado em Andrade (2003). A escolha da metodologia PDCA para o atendimento das metas deveuse principalmente ao fato de a empresa já ter uma cultura anterior de utilização da metodologia PDCA em processos de melhoria, minimizando a necessidade de novos gastos com treinamentos para difusão de outra metodologia. Conforme seu nome sugere, é composta por quatro etapas: planejar, fazer, verificar e agir. Na etapa de planejamento é essencial uma análise do processo produtivo para identificação de problemas e a busca de soluções para esses problemas que impliquem em melhorias dos índices de desempenho propostos. Através da análise do processo foram identificados alguns problemas que, direta ou indiretamente, impactavam sobre os indicadores anteriormente mencionados, a saber: fornecimento de peças remanufaturadas com qualidade deficiente para a área de montagem final; deficiência nos critérios de aceitação dos cartuchos recolhidos do campo; processos de trabalho pouco formalizados ou desatualizados; inexistência de uma etapa de limpeza de peças micro; conceito de ratio não incorporado 
ao planejamento da produção. Na Figura 2, através do diagrama de Ishikawa (1986), esses problemas formam três grupos associados com a seguinte gama de efeitos: processo não racionalizado, qualidade deficiente dos produtos remanufaturados e planejamento inadequado da produção. Nesse processo de mapeamento dos defeitos, os operadores participaram de forma ativa, através de seções de brainstorming. Essa ferramenta, descrita por Godoy (2001), consiste numa maneira disciplinada de envolver grupos de pessoas na geração de novas idéias.

$\mathrm{Na}$ busca das soluções para esses problemas, procurou-se, de acordo com Paladini (2004), soluções que procurassem eliminar as perdas, eliminar as causas das perdas e aperfeiçoar o processo. As soluções apresentadas podem ser agrupadas em três grupos distintos, sendo que cada um desses grupos faz referência aos três tipos de efeitos mostrados no diagrama de Ishikawa da Figura 2. O primeiro grupo, constituído por apenas uma solução, procurou a melhoria do efeito qualidade deficiente dos produtos remanufaturados, correspondente ao retângulo superior esquerdo da Figura 2. A solução encontrada foi a implantação de uma carta de CEP (Controle Estatístico do Processo) em todas as etapas do processo de remanufatura (limpeza fina, limpeza grossa e pré-montagem dos cartuchos). Na Figura 3 mostra-se um exemplo de carta de CEP para a etapa de limpeza fina.

O segundo grupo de soluções objetivou a melhoria do efeito processo produtivo não racionalizado e constituiuse de duas ações. A primeira delas foi a criação de uma estação exclusiva e com seqüência de operações padronizadas de inspeção e seleção de $100 \%$ das peças micro (peças pequenas) na área de limpeza fina. A segunda solução constituiu-se no desenvolvimento de ferramentas mais adequadas ao processo, na utilização de novos produtos químicos e na documentação detalhada das sequiências de operações nas etapas de limpeza grossa e fina. A obtenção dessa solução contou com a ajuda da ferramenta de qualidade brainstorming. Foram colhidas sugestões e idéias junto aos operadores das linhas e especialistas de produção quanto aos itens anteriormente citados.

O terceiro grupo de soluções objetivou obter uma melhoria do efeito planejamento inadequado da produção e constituiu-se de uma única ação, a implantação de um novo sistema informatizado de controle de estoque incorporando o conceito de ratio. O banco de dados do sistema foi desenvolvido com a ferramenta Oracle e a interface com o cliente foi construída utilizando-se a ferramenta Access. A arquitetura do sistema é de duas camadas, cliente-servidor. A interface com o cliente é constituída de sete telas e o banco de dados constituído de nove tabelas.

\section{A incorporação da informação do ratio no sistema informatizado de controle do estoque permitiu estabelecer um melhor planejamento do suprimento de peças remanufaturadas e de peças novas para a linha de produção.}

Tabela 2: Indicadores de desempenho e metas.

\begin{tabular}{|l|l|l|c|}
\hline \multicolumn{1}{|c|}{ INDICADOR } & \multicolumn{1}{|c|}{ DEFINIÇÃO } & \multicolumn{1}{|c|}{ OBJETIVOS ESTRATÉGICOS } & META \\
\hline $\begin{array}{l}\text { Aproveitamento de } \\
\text { Entrada }\end{array}$ & $\begin{array}{l}\text { (Quantidade de peças aproveitadas/ } \\
\text { Quantidade de peças recolhidas]x100 }\end{array}$ & $\begin{array}{l}\text { Aumentar o aproveitamento do } \\
\text { material recebido }\end{array}$ & $80 \%$ \\
\hline Nível de Defeitos & $\begin{array}{l}\text { (Quantidade de defeitos/Quantidade } \\
\text { produzida por dia)x100 }\end{array}$ & Aumentar a produtividade & $1,80 \%$ \\
\hline Nível de Entrega & $\begin{array}{l}\text { Percentual de atendimento dos } \\
\text { pedidos do mês }\end{array}$ & Melhorar as entregas no prazo & $100 \%$ \\
\hline
\end{tabular}


A avaliação dos resultados, que constitui a terceira etapa do ciclo PDCA, foi realizada comparando os resultados para os indicadores de desempenho antes e depois do processo de melhoria implantado. Na seção de resultados desse trabalho mostram-se os valores dos três indicadores antes e depois do processo de melhoria, enquanto que na seção discussão e conclusões avaliam-se esses resultados.

Em relação à etapa agir da ferramenta PDCA, as mudanças implantadas foram consolidadas através de uma ampla documentação das mesmas, da adequação de setores dentro da empresa para dar suporte às mudanças efetuadas no processo produtivo (por exemplo: programação de compras de novos produtos químicos) e realização de um trabalho de conscientização de todos os funcionários em relação à necessidade de cumprir o novo paradigma de produção estabelecido.

\section{RESULTADOS}

Os três indicadores anteriormente propostos foram avaliados mensalmente nos meses próximos anteriores e posteriores à implantação do processo de melhoria. A implantação das melhorias iniciou-se no mês de julho de
2003, sendo o mês de agosto de 2003 o primeiro mês em que a avaliação dos indicadores já reflete o efeito das mudanças. Na Figura 4 mostra-se o comportamento do indicador aproveitamento de entrada no período de março de 2003 a dezembro de 2003. Na Figura 5 mostra-se o comportamento do indicador nível de defeitos no período de janeiro de 2003 a abril de 2004. Na Figura 6 mostra-se o comportamento do indicador nível de serviço no período de janeiro de 2003 a março de 2004.

\section{DISCUSSÃO E CONCLUSÕES}

$\mathrm{O}$ processo de remanufatura de cartuchos de toner está longe de reutilizar 100\% das peças recolhidas. Conforme mostrado na Tabela 1, apenas as peças plásticas envolvidas no processo são reutilizadas, em um percentual variável, que depende do estado em que as mesmas se encontrem. Todo o material elétrico é substituído, pois os componentes elétricos do cartucho remanufaturado devem ter o mesmo tempo de vida útil que aqueles do produto manufaturado. Mesmo considerando esses dados, a economia de custos que se faz em termos de matéria-prima, conforme salientado na introdução, é da ordem de $45 \%$.

Figura 2: Diagrama de Ishikawa dos problemas identificados no processo de remanufatura.

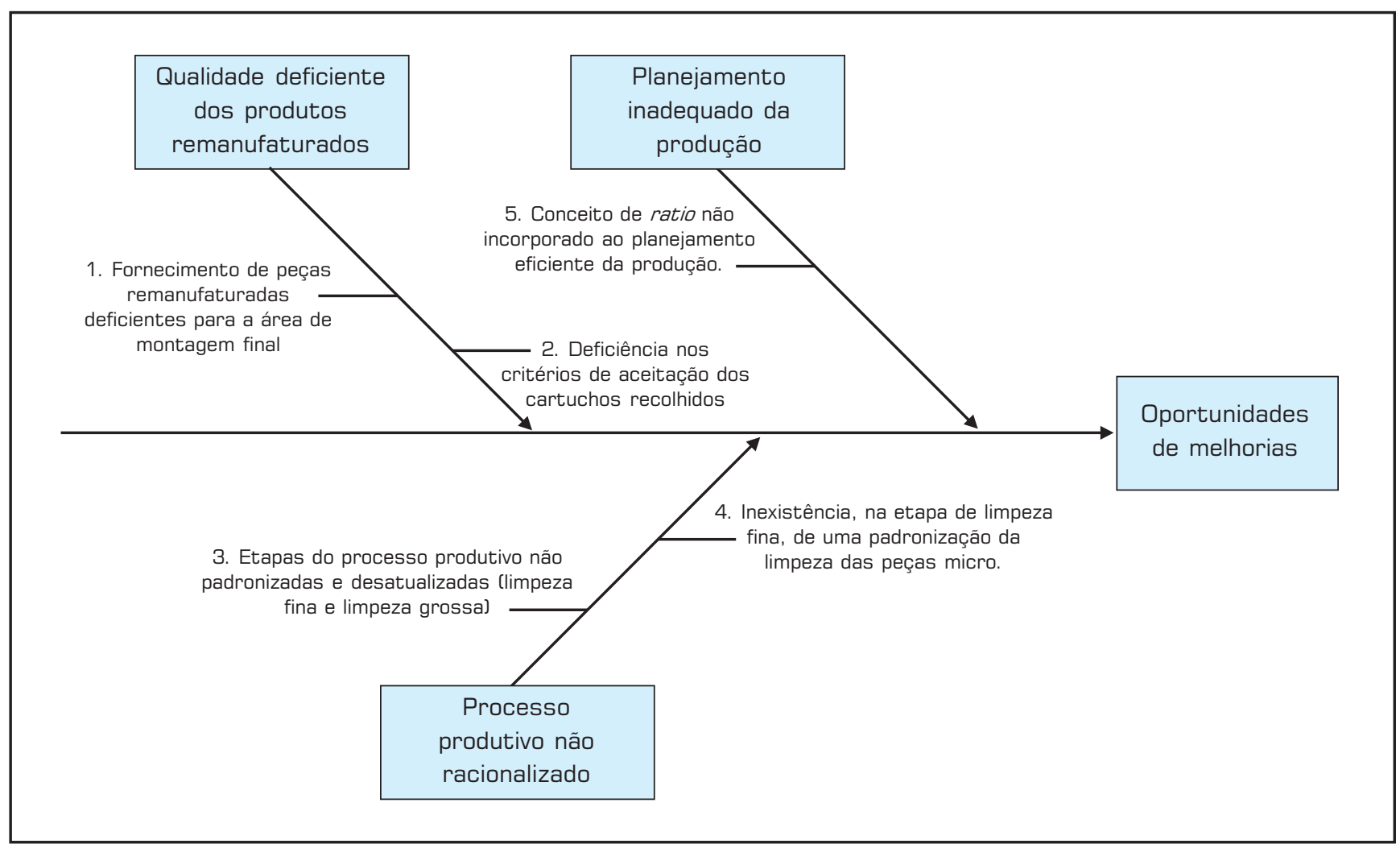


O diagnóstico e as soluções propostas para a melhoria do processo produtivo mostraram-se de grande eficácia no cumprimento das metas estabelecidas para os indicadores de desempenho. De uma forma geral, após a implantação das melhorias, tanto o nível de serviço quanto o aproveitamento de entrada tiveram ganhos superiores a $12 \%$. O nível de defeitos ficou oscilando entre valores menores do que a meta preestabelecida de $1,8 \%$.

A melhoria do indicador aproveitamento de entrada, observada a partir do mês de agosto de 2003 no gráfico da Figura 4, deveu-se à implantação da carta de CEP na área de limpeza grossa. Com a implantação dessa carta de CEP os fornecedores de peças usadas passaram a ser continuamente informados sobre os defeitos registrados

Figura 3: Carta de CEP utilizada na etapa de limpeza fina do cartucho de toner Hodaka.

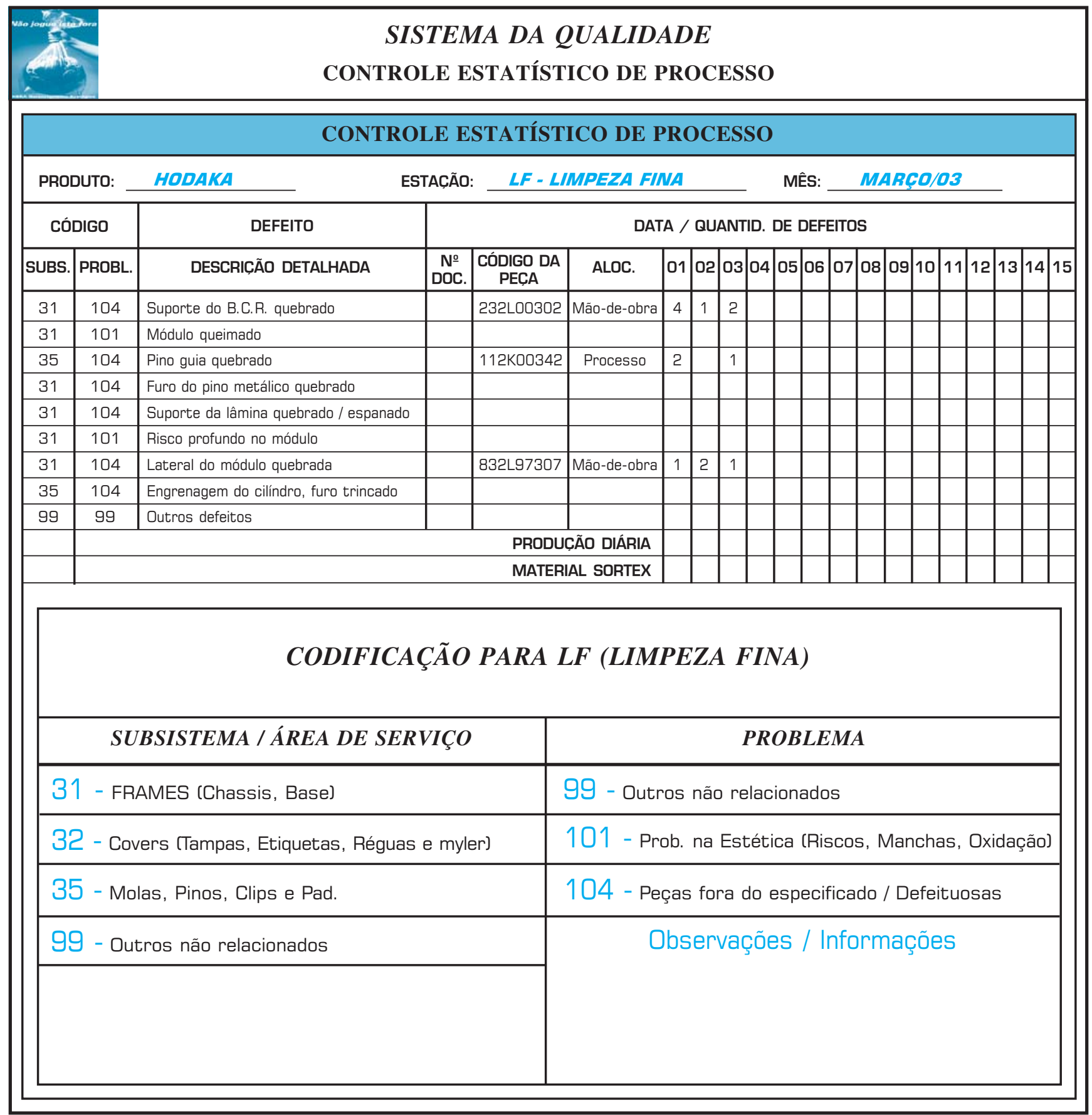


na entrada das mesmas na fábrica. De acordo com o gráfico mostrado na Figura 4, a meta estabelecida para o indicador aproveitamento de entrada foi atingida a partir do mês de setembro de 2003, tendo o seu valor permanecido acima de $80 \%$ a partir dessa data.

Por outro lado, a implantação da carta de CEP na área de limpeza fina e pré-montagem de cartuchos possibilitou obter um melhor mapeamento dos defeitos nessas áreas, com a priorização de critérios de seleção de peças boas dirigidos para os defeitos mais freqüentes. Essa ação teve um efeito significativo na melhoria do índice de desempenho nível de defeitos. De acordo com o gráfico mostrado na Figura 5, a meta estabelecida para o indicador nível de defeitos foi alcançada no mês de outubro de 2003, quatro meses após o início da implantação do processo de melhoria. A oscilação verificada no indicador índice de defeitos no mês de dezembro de 2003 mostra que o processo de melhoria exige um monitoramento e uma necessidade de adaptação contínua.

A incorporação da informação do ratio no sistema informatizado de controle do estoque permitiu estabelecer um melhor planejamento do suprimento de peças remanufaturadas e de peças novas para a linha de produção. Trabalha-se sempre procurando suprir todas as necessidades da produção com peças usadas. Para tanto, é necessário fornecer um número de cartuchos usados maior do que a quantidade a ser produzida. A quantidade a mais é determinada pelo valor do ratio das peças. Não havendo disponibilidade de cartuchos usados, inseremse peças novas na produção. Com um planejamento mais adequado da produção ocorreu uma melhoria substancial do indicador nível de serviço. De acordo com o gráfico mostrado na Figura 6, a meta estabelecida para o indicador nível de serviço foi alcançada a partir de janeiro de 2004 , tendo permanecido no valor de $100 \%$ até o final do período observado.

Os resultados do processo de melhoria implantado podem ser avaliados não só através dos indicadores quantitativos propostos, mas também de forma qualitativa, considerando que:

- Houve uma redução de problemas operacionais;

- Ocorreu uma melhoria da motivação dos funcionários, reforçando o envolvimento e o interesse dos mesmos no sentido de alcançar as metas estabelecidas pela empresa;

- Houve uma adequação do processo de remanufatura aos requisitos solicitados pelos processos de auditorias internas e externas;

Sumariando, esse trabalho propôs e implantou indicadores de desempenho apropriados a um processo de remanufatura de cartuchos de toner, cujos valores iniciais baixos foram melhorados de forma significativa através de

Figura 4: Gráfico do comportamento do indicador aproveitamento de entrada no período de março de 2003 a dezembro de 2003.

Aproveitamento de entrada

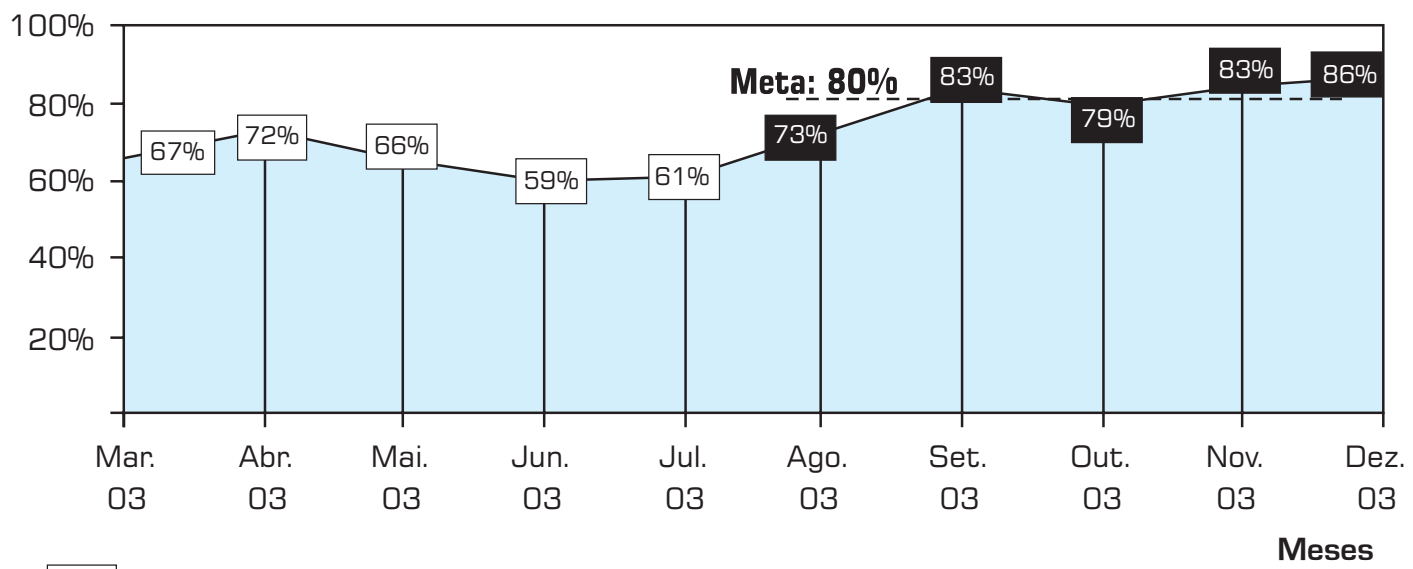

Meses anteriores ao processo de melhoria

Meses posteriores ao processo de melhoria 
um processo de melhoria. Nesse processo, foi essencial a identificação de novos pontos de inspeção sugeridos através do controle estatístico de processo. Por outro lado, o projeto e implantação de um novo sistema de informática que incorporou a idéia de ratio foram de suma importância para o planejamento da atividade de remanufatura.

Figura 5: Gráfico do comportamento do indicador nível de defeito no período de janeiro de 2003 a abril de 2004.

Nivel de defeitos

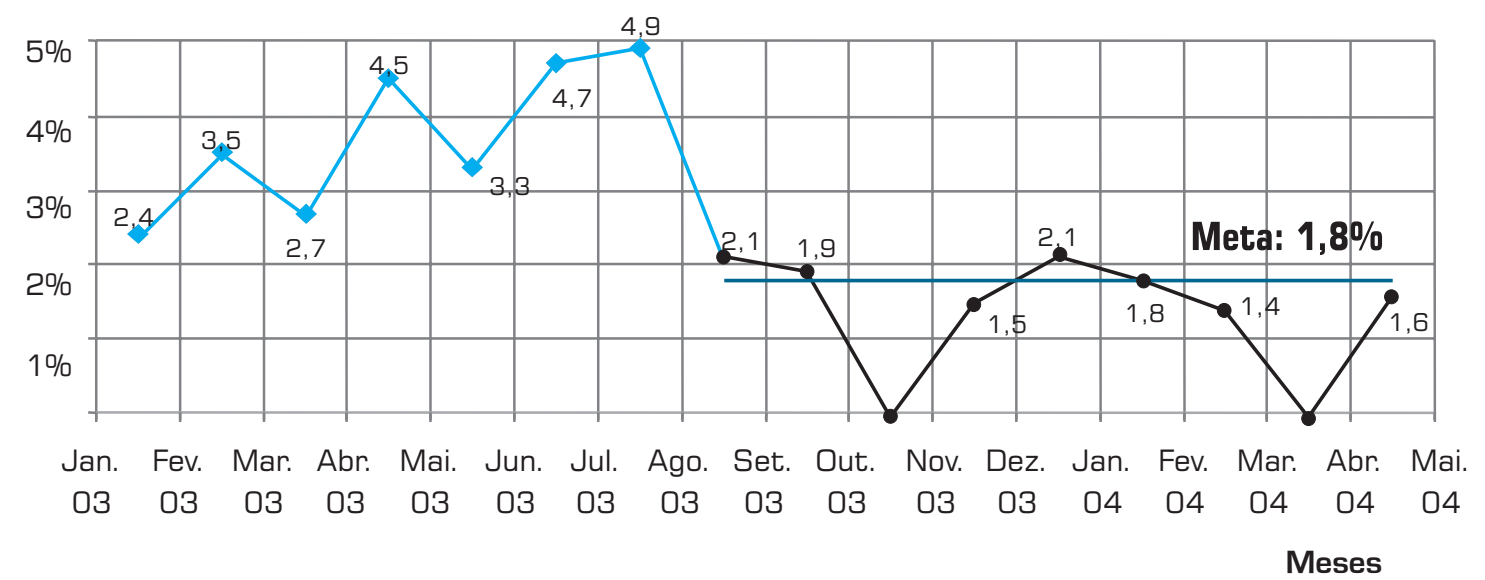

$\neg$ Meses anteriores ao processo de melhoria

Meses posteriores ao processo de melhoria

Figura 6: gráfico do comportamento do indicador nível de serviço no período de janeiro de 2003 a março de 2004.

Nível de serviço

Meta: $100 \%$

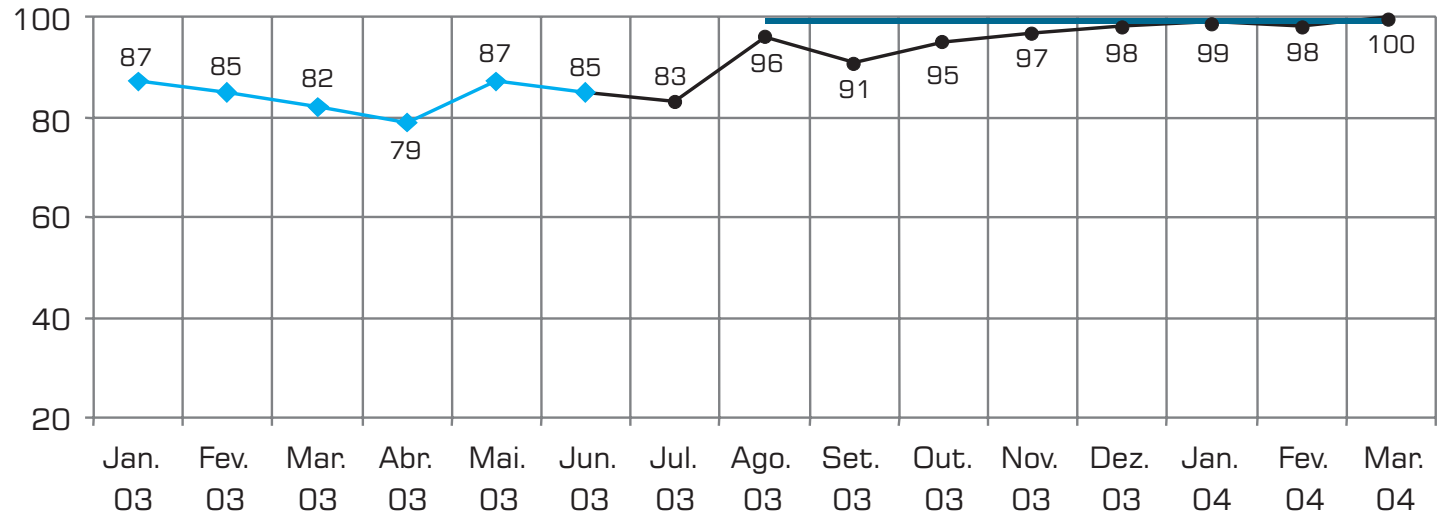

Meses

\footnotetext{
$\neg-$ Meses anteriores as melhorias

$\rightarrow-$ Meses posteriores as melhorias
} 
Artigo recebido em 18/04/2005

Aprovado para publicação em 21/12/2005

\section{- Referências Bibliográficas}

ANDRADE, Fábio Fellipe. 0 método de melhorias PDCA. Dissertação (Mestrado em Engenharia) - Escola Politécnica da Universidade de São Paulo, São Paulo, 2003.

DEMING, W. Edwards. Qualidade: Revolução da Administração. São Paulo: Editora Saraiva, 1992.

GODOY, Maria Helena Coelho. Brainstorming. Belo Horizonte: Editora de Desenvolvimento Gerencial, 2001

HANAFIAH, Lian Yi-Chen; NARITA, Hirohisa e FUJIMOTO, Hideo. Remanufacturing in developing countries concentrated at leasing or selling - a case study of Indonesia. Proceedings of EcoDesign 2003: $3 r$ d International Symposium on Environmentally Conscious Design and Inverse Manufacturing, Tokio, p. 5660, dez. 2003
ISHIKAWA, Kaoru. TQC, total quality control: Estratégia e Administração do Qualidade. São Paulo: IMC Internacional Sistemas Educativos, 1986.

KIYAN, Fábio Makita. Proposta para desenvolvimento de indicadores de desempenho como suporte estratégico. Dissertação (Mestrado em Engenharia de Produção) - Universidade de São Carlos, São Carlos, 2001.

MARCELLI, Ricardo Pereira. O papel dos indicadores de desempenho na estratégia das organizações para o aprimoramento de processos: um estudo de caso. Dissertação (Mestrado em Engenharia de Produção) - Universidade federal de Santa Catarina, Florianópolis, 2000.

NAGANO, Mario. Falsificação de cartuchos. Revista Recicla Mais, São Paulo, vol.1, 2000.
PALADINI, Edson Pacheco. Gestão da Qualidade. São Paulo: Atlas, 2004.

RELATÓRIO PLANETA VIVO, WWF, 2004. Disponível em: <http:// www.panda.org/downloads/general/ wwfrelatorioplanetavivo2004.pdf > Acesso em: 23 março 2005.

STEINHILPER, Rolf. Recent trends and benefits of remanufacturing: from closed loop businesses to synergetic networks. Proceedings of the IEEE Second International Symposium on Environmentally Conscious Design and Inverse Manufacturing, Tokio, p. 481488, dez. 2001.

STEINHILPER, Rolf; BRENT, Alan. Saving product lives in global and local remanufacturing networks: a scientific and commercial work report and an outlook. Proceedings of EcoDesign 2003: Third International Symposium on Environmentally Conscious Design and Inverse Manufacturing, Tokio, p. 297-302, dez. 2003.

WILLIAMS, David; SHU, Lily. Analysis of toner-cartridge remanufacturer waste stream. Proceedings of the IEEE International Symposium on Electronics and the Environment, San Francisco CA, Denver CO USA, p. 279-284, maio 2001.

WINIFRED, Ijomah; BENNET, Jan e PEARCE, Jim. Remanufacturing: evidence of environmentally conscious business practice in the UK. Proceedings of EcoDesign 1999: First International Symposium on Environmentally Conscious Design and Inverse Manufacturing, Tokio, p. 192 196, fev. 1999.

\section{- Sobre os autores}

\section{Cícero Ferreira Fernandes Costa Filho}

Universidade Federal do Amazonas

Professor Adjunto

Endereço: Centro de Tecnologia Eletrônica e da Informação - Universidade Federal do Amazonas

Av. Rodrigo Otávio Jordão Ramos, 3000 - Aleixo - Manaus - AM - CEP 69077-000

Telefone: (92) 3647-4309, 3647-4413, 9146-4954

E-mail: cicero.costa@uol.com.br

\section{Luís Carlos Barros Coelho Júnior}

Xerox da Amazônia

Coordenador de Produção e Manutenção

Endereço: Xerox da Amazônia - Divisão de Supplies

Av. Grande Circular, 800 - Lote 3121 - Distrito Industrial - Manaus - AM - CEP 69075-840

Telefone: (92) 4009-7700, 9982-8549

E-mail: luis.junior@bra.xerox.com

\section{Marly Guimarães Fernandes Costa}

Universidade Federal do Amazonas

Professora Adjunta

Endereço: Centro de Tecnologia Eletrônica e da Informação - Universidade Federal do Amazonas

Av. Rodrigo Otávio Jordão Ramos, 3000 - Aleixo - Manaus - AM - CEP 69077-000

Telefone: (92) 3647-4309, 3647-4413, 9128-2404

E-mail: marly.costa@uol.com.br 